Journal Homepage: http://pusdikra-publishing.com/index.php/jirss

\title{
STRATEGI MANAJEMEN PEMASARAN LEMBAGA PENDIDIKAN ISLAM DI MTS MADINATUL ILMI DESA LUBUK KERTANG KECAMATAN BERANDAN BARAT
}

\author{
Siti Mariani1 ${ }^{1}$, Ahmad Fuadi' ${ }^{2}$ Muhammad Saleh ${ }^{3}$ \\ 1,2,3,STAI Jam'iyah Mahmudiyah
}

\section{ABSTRACT}

Interesting events occur in the administration of education, especially during the acceptance of new students. The community seems to have understood that madrasas are suitable for sending their sons/daughter to school, for them the criteria for madrasas that have a good image are madrasas that have succeeded in satisfying users of educational services. The focus of this research are: 1) How is the strategy of educational services in improving the image of Islamic educational institutions at MTs Madinatul Ilmi? 2) How is the marketing management strategy of Islamic educational institutions at MTs Madinatul Ilmi? 3) How is the impact of the marketing management strategy of Islamic educational institutions at MTs Madinatul Ilmi for the community?. This research includes qualitative research, the type of case study with a multi-case design. The data collection process used the method of observation, in-depth interviews and documentation. Data analysis used the Miles and Huberman model, the data collected and checked for validity were analyzed by means of date reduction, data presentation and conclusion drawing. Checking the data using the triangulaton method. While the result of this study are: First, Educational services at MTs Madinatul Ilmi prioritize efforts to fulfill customer expectations and satisfaction, this is indicated bay 3 things, namely satisfaction with academic quality services, satisfaction with standardization of teachers and madrasas administrative staff and quality satisfaction of graduates. Second, The marketing strategy in improving the image is carried out by several strategy, and financing strategy. However, an effective strategy at MTs Madinatul Ilmi is to show evidence of the quality of graduates and build an image of service satisfaction through word of mouth. Third, The impact of the marketing strategy and its implications for imaging at MTs Madinatul Ilmi are high customer loyalty for education service users, stronger public trust, community support and effective collaboration between madrasas and parent.

Kata Kunci

$$
\text { Islamic Educational, Institutions, Educational Marketing }
$$

\section{PENDAHULUAN}

Pemasaran lembaga pendidikan Islam, khususnya lembaga madrasah, belum terlalu banyak menjadi bahan diskusi bahwa hampir diabaikan oleh para sarjana maupun pengelola lembaga-lembaga pendidikan Islam. Pemasaran dalam dunia pendidikan terdengar belum 
sering di telinga masyarakat kita, karena umumnya istilah pemasaran ini lebih umum di dunia bisnis atau perusahaan. Dalam hal ini, pendidikan adalah usaha yang tidak berorientasi pada mencari keuntungan, akan tetapi berorientasi pada pelayanan jasa pendidikan.

Pada mulanya, pemasaran ini dikenal dan dikembangkan oleh perusahaan besar dengan kekuatan ekonomi yang besar pula. Akan tetapi pada saat ini, setiap perusahaan dan bahkan setiap orang telah menggunakannya, demikan juga dengan lembaga pendidikan yang berfungsi sebagai pencetak biro jasa masa depan telah memanfaatkan segi keunggulan pemasaran untuk meningkatkan kerjasama mereka dengan masyarakat.

Pemasaran untuk lembaga pendidikan mutlak diperlukan (Wijaya, 2008). Alasannya yang pertama, sebagai lembaga nonprofit yang bergerak dalam bidang jasa pendidikan, untuk tingkat apa saja, kita perlu meyakinkan masyarakat dan pelanggan bahwa lembaga pendidikan yang kita kelola masih tetap eksis. Kedua, kita perlu meyakinkan bahwa layanan jasa pendidikan yang kita

lakukan sungguh relevan dengan kebutuhan mereka. Ketiga, kita perlu melakukan kegiatan pemasaran agar jenis dan macam jasa pendidikan yang kita lakukan dapat dikenal dan dimengerti secara luas oleh masyarakat, apalagi pelanggan. Keempat, agar eksistensi lembaga pendidikan yang kita kelola tidak ditinggalkan oleh masyarakat luas serta pelanggan potensial. Berdasarkan keterangan yang dikemukakan tersebut dapat dikatakan bahwa pemasaran dalam dunia pendidikan sudah menjadi suatu kebutuhan, agar lembaga pendidikan bisa dikenal dan mendapat tempat di hati masyarakat sehingga masyarakat mau menyekolahkan anak-anak mereka di lembaga pendidikan tersebut.

Pada dasarnya, produk yang dihasilkan oleh sekolah adalah jasa pendidikan dan lulusan, yang disajikan kepada siswa. Untuk diketahui bahwa produk sekolah bukan merupakan barang melainkan jasa pendidikan dan lulusan yang diberikan kepada siswa dan orang tua siswa. Jasa pendidikan memiliki karakteristik utama yaitu: tidak berwujud, tidak dapat dipisahkan, bervariasi dan tidak tahan lama.

Apabila dilihat batasan karakteristik jasa pendidikan, maka lembaga pendidikan termasuk dalam kategori lembaga pemberi jasa kepada para siswa dan orang tua siswa. Mereka inilah yang menilai apakah lembaga pendidikan tersebut dapat memenuhi kebutuhan mereka berupa pemberian layanan jasa pendidikan yang berorientasi pada mutu. Ada perbedaan dengan produk fisik, diamana jasa pelayanan pedidikan tidak 
bisa disimpan. Ini akan berpengaruh pada sistem pemasaran, terutama pada sisi permintaan. Apabila permintaannya stabil akan memudahkan penyedia jasa pendidikan untuk melakukan

persiapan, baik dari sarana dan prasarana maupun peralatan teknologi pendidikan lainnya. Akan tetapi, jika permintaan tidak stabil, akan menyulitkan bagi penyedia jasa pendidikan untuk melakukan strategi pemasaran. Jasa pendidikan tidak bisa dilihat dan dirasakan oleh konsumen sebelum konsumen membeli atau mendapatkan penyedia jasa pendidikan secara langsung. Konsumen juga tidak dapat memprediksi apa hasil yang akan diperoleh dengan mengonsumsi jasa pendidikan, kecuali setelah membeli atau menjadi pengguna jasa pendidikan tersebut.

Hal yang menjadi pertanyaan adalah siapakah yang seharusnya memutuskan, apakah sebuah lembaga pendidikan itu berhasil memberikan layanan yang memiliki mutu. Mutu dapat didefinisikan sebagai sesuatu yang memuaskan dan melampaui keinginan dan kebutuhan siswa dan orang tua siswa. Disini, siswa dan orang tua siswa inilah yang membuat keputusan terhadap mutu, artinya mereka adalah wasit terhadap mutu dan lembaga pendidikan tersebut. Mereka melakukan penilaian dengan merujuk pada produk terbaik yang bisa bertahan dalam persaingan.

Strategi pemasaran yang bagaimana yang akan dijadikan pijakan oleh suatu lembaga pendidikan, tentunya harus menyesuaikan dengan perkembangan lingkungan. Tantangan lembaga pendidikan Islam kedepan adalah adanya persaingan yang tinggi sehingga sangat banyak penawaran jasa lembaga pendidikan, meningkatnya tuntutan siswa pada kualitas dan biaya, kemajuan teknologi komunikasi, informasi dan komputer yang merubah semua segi kehidupan, dan lainnya. Pada akhirnya yang menjadi perhatian lembaga pendidikan adalah bagaimana dengan berbagai tantangan dan

keterbatasan masih mampu bertahan hidup dan berkembang. Jadi, lembaga pendidikan adalah lembaga yang bergerak dibidang layanan jasa pendidikan yang kegiatannya melayani siswa, mahasiswa dan masyarakat umum. Pemasaran pendidikan merupakan misi dari hubungan masyarakat di sebuah lembaga pendidikan untuk menarik minat siswa dan orang tua siswa.

Salah satu fungsi pemasaran di madrasah pada dasarnya adalah untuk membentuk citra baik terhadap lembaga dan menarik sejumlah calon siswa (Prabowo, 2008). Dengan demikian citra merupakan salah satu faktor dalam upaya pemasaran pendidikan yang berdampak positif 
terhadap peningkatan minat pengguna jasa pendidikan di lembaga pendidikan tersebut. Philip Kotler dalam Prabowo menyatakan bahwa image is power. Citra yang positif merupakan aset yang sangat berharga di pasar. Levy dalam Alma mengemukakan bahwa citra merupakan interpretasi, seperangkat pengetahuan dan rekreasi-rekreasi (Alma, 2007). Hal tersebut merupakan simbol karena hal tersebut bukan merupakan objek itu sendiri tetapi merujuk kepada objek tersebut. Selanjutnya kenyataan fisik produk, brand dan organisasi, citra termasuk makna, kepercayaan, sikap dan perasaan-perasaan terhadap sesuatu. Jadi citra dibentuk berdasarkan pengetahuan seseorang akan sesuatu sehingga membangun sikap mental yang akan merujuk kepada apa yang sudah diketahui tentang sesuatu itu.

Banyak sekali hal-hal yang menarik terjadi dalam penyelenggaraan pendidikan, baik di madrasah negeri maupun swasta terutama saat penerimaan peserta didik baru. Masyarakat seakan sudah mengerti madrasah yang layak

untuk menyekolahkan putra/putrinya. Bagi mereka kriteria madrasah yang memiliki citra yang baik adalah madrasah yang berhasil memuaskan para pengguna jasa pendidikan. Hal inilah yang menjadi tugas kepala madrasah khususnya bidang hubungan masyarakat madrasah untuk melakukan pemasaran jasa pendidikan agar mendapat citra yang diharapkan oleh masyarakat. Sehingga ada sebagian orang tua siswa yang setia menjadi pelanggan di suatu madrasah. Ini terjadi karena orang tua siswa puas akan pelayanan pendidikan yang diberikan madrasah tersebut. Saat ini banyak sekolah atau madrasah yang membuka penerimaan peserta didik baru dari jauh-jauh hari, ini disebabkan tingginya keinginan masyarakat untuk menyekolahkan anak mereka di lembaga pendidikan yang memiliki citra yang baik.

Dari hasil studi pendahuluan yang dilakukan di MTs Madinatul Ilmi Desa Lubuk Kertang Kecamatan Berandan Barat, MTs ini memiliki citra yang positif atau baik bagi masyarakat sekitar dan di Kecamatan Berandan Barat. Sehingga orang tua siswa memilih MTs Madinatul Ilmi ini untuk memberikan pendidikan kepada putra/putrinya. Banyak perubahan besar terjadi baik secara fisik, sarana prasarana dan fasilitas belajar mengajar, gedung dan manajemen operasional, peningkatan peran serta masyarakat, terlebih lagi prestasinya. Setiap tahunnya MTs Madinatul Ilmi ini mengalami ketidakstabilan atau tidak menentunya jumlah siswa baru, terkadang mengalami peningkatan maupun penurunan. Salah satu bukti pemasarannya yang mengalami 
ketidakstabilan adalah karena adanya data peserta didik baru selama empat tahun terakhir mengalami ketidaktsabilan, melalui wawancara dengan kepala sekolah MTs Madinatul Ilminya langsung yakni pada tahun ajaran 2017/2018 jumah pendaftar hanya 36 peserta didik, selanjutnya pada tahun ajaran 2018/2019 jumlah pendaftar mengalami penurunan yaitu 35 peserta didik, pada tahun ajaran 2019/2020 jumlah pendaftar mengalami kenaikan yaitu 40 peserta didik, kemudian pada tahun terakhir yaitu tahun ajaran 2020/2021 jumlah pendaftar mengalami penurunan menjadi 35 peserta didik. Berdasarkan data tersebut untuk mengetahui bahwa di MTs Madinatul Ilmi mengalami ketidakstabilan jumlah pendaftar peserta didik baru yang akan ditempatkan di kelas VII.

Tempat penelitian ini diambil karena memiliki citra yang baik atau citra yang positif. MTs Madinatul Ilmi menawarkan fasilitas dan layanan pendidikan yang berorientasi pada kepuasan pelanggan. Berbagai program-program unggulan ditawarkan mulai dari sistem kelas kecil, sistem kedisiplinan, sistem raport bulanan dan lain sebagainya. Melalui program-program andalan tersebut, MTs Madinatul Ilmi berupaya meningkatkan citra dan penilaian yang positif dari masyarakat.

Dari hasil pengamatan pralapangan ditemukan beberapa keunikan tentang strategi pemasaran lembaga pendidikan Islam di tempat penelitian. Di MTs Madinatul Ilmi, sekolah swasta yang termasuk MTs yang baik di Kecamatan Berandan Barat ini dalam menjalankan strategi pemasaran pendidikan banyak melibatkan pihak yayasan walaupun di MTs ini sendiri sudah ada wakil kepala bidang hubungan masyarakat. Teknik promosi biasanya menyebarkan brosur MTs sebagai media pemasarannya. Berdasarkan uraian tersebut ingin diketahui bagaimana strategi pemasaran lembaga

pendidikan Islam di MTs Madinatul Ilmi. Oleh karena itu dilakukanlah penelitian tentang Strategi Manajemen Pemasaran Lembaga Pendidikan Islam di MTs Madinatul Ilmi Desa Lubuk Kertang Kecamatan Berandan Barat.

\section{METODE PENELITIAN}

Jenis penelitian yang digunakan adalah penelitian kualitatif. Menurut Moleong penelitian kualitatif adalah prosedur penelitian yang digunakan untuk memahami tentang fenomena yang dialami oleh subjek penelitian, berupa perilaku, motivasi dan tindakan yang dapat menghasilkan data deskriptif seperti kata-kata tertulis atau lisan, kalimat dan pendapat-pendapat (Moleong, 2011). 
Penelitian kualitatif adalah proses penyelidikan naturalistik yang mencari pemahaman mendalam tentang fenomena sosial dalam pengaturan alaminya. Ini berfokus pada fenomena sosial dan bergantung pada pengalaman langsung manusia sebagai agen pembuat makna dalam kehidupan sehari-hari mereka. Penggunaan penelitian kualitatif adalah untuk mendapatkan pemahaman tentang alasan, pendapat, dan motivasi yang mendasarinya.

Menurut Imam Gunawan penelitian kualitatif bertujuan untuk mendapatkan pemahaman yang mendalam tentang masalah-masalah manusia dan social, bukan mendeskripsikan bagian permukaan dari suatu realitas sebagaimana dilakukan oleh penelitian kuantitatif (Gunawa, 2014). Adapun data dalam penelitian kualitatif dapat dinyatakan dalam bentuk kata, kalimat, dan gambar (Gunawan, 2014).

Penelitian ini mengangkat masalah strategi manajemen pemasaran pendidikan Islam yang dilakukan di MTs Madinatul Ilmi Desa Lubuk Kertang Kecamatan Berandan Barat. Fokus penelitian ini menggunakan jenis kualitatif yang mengarah pada penjelasan panjang bebas dan menyeluruh jenis studi kasus dengan rancangan multikasus. Penelitian ini ingin mengetahui, mempelajari dan memahami strategi pemasaran pendidikan Islam dalam meningkatkan citra dengan menggunakan pendekatan studi kasus.

\section{HASIL DAN PEMBAHASAN}

Pendidikan sebagai produk jasa merupakan sesuatu yang tidak berwujud akan tetapi dapat memenuhi kebutuhan konsumen yang diproses dengan menggunakan atau tidak menggunaan bantuan produk fisik dimana proses yang terjadi merupakan interaksi antara penyedia jasa dengan pengguna jasa yang mempunyai sifat tidak mengakibatkan peralihan hak atau kepemilikan. Pelayanan adalah inti dari transaksi di bidang jasa. Karena pelayanan merupakan kegiatan yang ditawarkan oleh pihak penyelenggara jasa kepada konsumen atau pemakai jasa dalam rangka memenuhi kebutuhan dan kepuasan pelanggan. Kepuasan dalam menerima layanan menjadi kehendak bagi setiap konsumen atau penerima layanan.

Pemasaran merupakan suatu proses dimana seseorang atau kelompok dapat memenuhi keinginan melalui usaha mempengaruhi, menyalurkan, dan memindahkan kepemilikan dari satu orang ke orang lain atau antar kelompok baik dalam masalah barang atau jasa. Fungsi pemasaran di lembaga pendidikan adalah untuk membentuk citra baik 
terhadap lembaga dan menarik minat sejumlah calon siswa. Oleh karena itu, pemasaran harus berorientasi kepada pelanggan yang dalam konteks madrasah disebut dengan siswa. Di sinilah perlunya madrasah untuk mengetahui bagaimanakah calon siswa melihat madrasah yang akan dipilihnya.

Temuan-temuan yang didiskusikan pada bab ini sesuai dengan fokus penelitian yaitu sebagai berikut:

\section{Layanan Jasa Pendidikan di MTs Swasta Madinatul Ilmi}

Berdasarkan hasil penelitian yang peneliti temukan di MTs Madinatul Ilmi dapat disimpulkan bahwa layanan jasa di MTs Swasta Madinatul Ilmi sudah sangat baik dan memenuhi bahkan melebihi harapan pengguna jasa pendidikan di lembaga tersebut. Karena lembaga pendidikan ini memberikan layanan yang berkualitas dan memenuhi kebutuhan serta keinginan masyarakat sebagai pengguna jasa pendidikan.

\section{Strategi Pemasaran Pendidikan di MTs Swasta Madinatul Ilmi}

Strategi yang diterapkan di MTs Swasta Madinatul Ilmi dalam memasarkan jasa pendidikannya adalah dengan melakukan kegiatan spesifik yang dikembangkan oleh MTs Swasta Madinatul Ilmi agar lebih unggul dibandingkan dengan pesaingnya. Adapun keunggulan-keunggulan MTs Swasta Madinatul Ilmi tertuang dalam visi dan misi madrasah.

Teknik promosi di MTs Swasta Madinatul Ilmi dengan penyebaran brosur dan melakukan promosi di media sosial, namun demikian promosi yang paling menjamin adalah berita dari mulut ke mulut. MTs Swasta Madinatul Ilmi menonjolkan prestasi-prestasi yang diraih melalui berbagai macam event baik di tingkat nasional maupun internasional. Sehingga demikian citra positif MTs Swasta Madinatul Ilmi terbukti sudah terkesan di mata masyarakat secara tidak langsung sekolah sudah mengiklankan dirinya melalui prestasi-prestasi yang diperoleh.

Kerjasama antara sekolah dan wali murid di MTs Swasta Madinatul Ilmi dibentuk organisasi wali murid yaitu komite madrasah. Kerjasama antar wali murid dalam wadah komite ini memberikan kontribusi yang positif terhadap perkembangan madrasah dalam segala bidang. Selain itu, ada kesempatan kepada wali murid untuk mengajar di kelas sesuai profesi atau keahlian yang dimiliki.

3. Dampak Strategi Pemasaran Dan Implikasinya Terhadap Pencitraan Lembaga di MTs Swasta Madinatul Ilmi

Meningkatnya kepercayaan masyarakat terhadap lembaga pendidikan. Indikatornya animo masyarakat yang besar untuk dapat menggunakan layanan jasa pendidikan di MTs Swasta Madinatul Ilmi. 
Tingginya animo masyarakat bisa diketahui dengan banyak calon orang tua siswa yang mulai mendaftarkan putra/putrinya di MTs Madinatul Ilmi.

1) Adanya dukungan dan kerja sama masyarakat khususnya wali murid. Setiap kegiatan apapun yang diselenggarakan MTs Swasta Madinatul Ilmi selalu didukung oleh wali murid. Biasanya wali murid yang punya usaha apa atau profesi apa nanti anak-anak diajak belajar mengenai usaha atau profesi wali murid tersebut, atau ketika mengikuti kegiatan diluar maka wali murid ikut membantu bagaimana transportasinya, konsumsinya dan lain-lain.

2) Adanya loyalitas dan komitmen dari masyarakat khususnya pengguna jasa pendidikan di MTs Swasta Madinatul Ilmi. Banyak dari orang tua siswa yang menjadi pelanggan setia di MTs Swasta Madinatul Ilmi, biasanya kakaknya yang sudah masuk di MTs Swasta Madinatul Ilmi adiknya pun dimasukkan di sekolah yang sama. hal ini merupakan bentuk loyalitas para orang tua siswa.

\section{KESIMPULAN}

Berdasarkan hasil penelitian dan pembahasan diketahui bahwa tingginya minat masyarakat terhadap MTs Swasta Madinatul Ilmi merupakan buah keberhasilan dari lembaga pendidikan dalam memberikan pelayanan yang terbaik kepada masyarakat khususnya kepada siswa dan orang tua siswa. Berdasarkan paparan hasil temuan penelitian maka dapat peneliti simpulkan beberapa hal untuk menjawab fokus penelitian yang telah dirumuskan diawal yaitu:

1. Layanan jasa pendidikan di MTs Swasta Madinatul Ilmi memprioritaskan pada upaya memenuhi harapan dan kepuasan pelanggan, hal ini dapat diindikasikan dari 3 hal, yaitu layanan mutu akademik, standarisasi guru dan Staf Tata Usaha madrasah dan mutu lulusan.

2. Strategi Pemasaran dalam meningkatkan citra MTs Swasta Madinatul Ilmi dilakukan dengan strategi langsung dan tidak langsung. Strategi langsung yaitu melakukan promosi dengan menyebarkan brosur, memasang spanduk dan melakukan promosi melalui media sosial. Promosi tidak langsung dengan mengadakan beberapa even seperti gebyar maulid, mengikuti even lomba baik tingkat kecamatan, kabupaten dan provinsi. Namun demikian 
stategi yang efektif di MTs Swasta Madinatul Ilmi adalah dengan menunjukkan bukti kualitas lulusan dan membangun citra kepuasan layanan melalui berita dari mulut ke mulut.

3. Dampak strategi pemasaran dan implikasinya terhadapa pencitraan MTs Swasta Madinatul Ilmi ialah kepercayaan masyarakat semakin kuat terhadap MTs Madinatul Ilmi, adanya dukungan dan kerja sama dari masyarakat, khususnya orang tua siswa dalam setiap kegiatan atau even madrasah serta adanya komite madrasah dan tingginya loyalitas pelanggan pengguna jasa pendidikan yang ikut membantu memasarkan pendidikan dari mulut ke mulut dan menjadi pelanggan setia yang kembali menggunakan jasa pendidikan di lembaga MTs Swasta Madinatul Ilmi.

\section{DAFTAR PUSTAKA}

Al Qur'anul Karim

Alma, Buchari. Pemasaran Stratejik Jasa Pendidikan. Bandung: Alfabeta. 2003.

Alma, Buchari. Manajemen Pemasaran Dan Pemasaran Jasa. (Bandung: Alfabeta, 2007).

Arikunto, S. Prosedur penelitian; suatu pendekatan praktek. (Jakarta: Rineka Cipta, 2002).

Depag RI. Al-qur'an dan Terjemahnya. (Jakarta: Depag RI, 1995).

Gunawan, Imam. Metode Penelitian Kualitatif : Teori dan Praktek. (Jakarta : Bumi Aksara, 2014).

Handoko, T. Hani. Manajemen Personalia dan Sumber Daya Manusia, (Yogyakarta: BPFE, 2000).

Hasibuan, Malayu S.P. Manajemen Sumber Daya Manusia. (Jakarta: Bumi Aksara, 2000).

Moleong, Lexy J. Metodologi Penelitian Kualitatif. (Bandung: Rosdakarya, 2006).

Moleong, Lexy J. Metodologi Penelitian Kualitatif, Edisi Revisi. (Bandung : Remaja Rosdakarya, 2011).

Muhaimin. Manajemen Pendidikan: Aplikasinya dalam penyusunan Rencana Pengembangan sekolah/Madrasah. (Jakarta: Kencana, 2011).

Mulyadi. Kepemimpinan Kepala Sekolah dalam mengembangkan budaya mutu. (Malang: UIN-Maliki Press, 2010).

Nasution. Metode Penelitian Naturalistik Kualitatif. (Bandung : Tarsito, 2003). 
Cybernetics: Journal Educational Research and Social Studies

Prabowo, LS. . Manajemen Pengembangan Mutu Sekolah/Madrasah. (Malang: UIN-Malang Press, 2008).

Sallis, E. Total Quality Management in Education (Manajemen Mutu Pendidikan), (Jogjakarta; IRCiSoD, 2012).

Sugiyono. Statistika Untuk Penelitian. (Bandung: CV. Alfabheta, 2006).

Sutisna. Membangun Layanan Manajemen yang Ideal. (Bandung : Pustaka Andia, 1995).

Tjiptono, Fandy. Manajemen Jasa. (Yogyakarta: Andi, 2000).

Tjiptono, Fandy. Strategi Pemasaran. Edisi Pertama. (Yogyakarta: Andi Ofset, 2001).

Wijaya, David. Pemasaran Jasa Pendidikan Sebagai Upaya untuk Meningkatkan Daya Saing Sekolah. Jurnal Pendidikan PenaburNo.11/Tahun ke-7/Desember, 2008. 